\title{
Thrombolytic therapy in acute myocardial infarction
}

\section{Paul Oldershaw}

Brompton Hospital, London SW3 6HP, UK.
Infarct size limitation has been a therapeutic aim for many years, particularly in view of the known close relationship between the extent of myocardial damage occurring at the time of the infarction, and future morbidity and mortality. It is only in the last decade, however, since the pathophysiology of myocardial infarction has been better understood, that this aim has become a clinical reality. Thus, it is now well established that myocardial infarction is caused by intracoronary thrombosis, usually at the site of a ruptured atheromatous plaque, ${ }^{1-3}$ and this occlusive thrombus can be dissolved by the administration of intracoronary or intravenous thrombolytic agents. ${ }^{4-6}$.

Although this clinical breakthrough has come in the last 10 years, the pioneering work on this subject was in fact performed in the late 1950s and early 1960s, using open chested anaesthetized dogs to study the effects of reperfusion on ischaemic myocardium. ${ }^{7-11}$ The results of these early studies demonstrated the experimental basis for the theory that ischaemic cell death has an early reversible and later irreversible phase. However, it was not until the late 1970s that a full analysis of the timing of cell death was complete and a time frame for intervention to reduce infarct size established. ${ }^{12-14}$ Reimer and Jennings, ${ }^{14}$ in a classical paper, were at this time able to produce, from animal studies, a plot of the percentage of myocardium salvageable (by reperfusion) against duration of occlusion of a coronary artery. This work clearly demonstrated a therapeutic time window in which intervention was able to modify infarct size and it was from this paper, together with work showing the role of occlusive thrombus resulting in myocardial infarction, ${ }^{1-3}$ that a number of clinical studies on infarct size limitation were moulded.

Correspondence: P. Oldershaw, M.B., B.Chir., M.R.C.P. Based on a lecture given to the European Medical Research Group on 7 June 1988
Initial human work on this subject in the early 1980s was largely confined to the administration of intracoronary streptokinase $e^{4,6,15,16}$ and it therefore required that medical practitioners involved in the work had access to a cardiac catheterization laboratory. In these studies, intracoronary streptokinase was infused into the occluded coronary artery at a standard rate, and patency rates achieved were in the region of $70-80 \%$ after 20-30 minutes perfusion. It was realized early on however that the assessment of success in restoring coronary patency was complicated by the phenomenon of spontaneous reperfusion. ${ }^{17,18}$ However, in the many studies performed at this time, coronary patency rates were consistently significantly higher after the administration of thrombolytic therapy than in patients treated conventionally.

Because of logistic problems with intracoronary infusions the obvious next development for thrombolytic therapy was the utilization of the intravenous route of administration. Streptokinase given in this way achieved a slightly reduced patency rate $(55-75 \%)$ as compared to intracoronary streptokinase ${ }^{19,20}$ but it was clear that if treatment was given to patients in the critical first few hours after infarction then limitation of infarct size was possible. ${ }^{6}$ The most popular regimen used for the administration of intravenous streptokinase was that developed by Schroder et $a l .{ }^{5}$ based on the earlier work of Breddin ${ }^{21}$; using this regime, one and a half million units of streptokinase are given by slow intravenous infusion over 60 minutes.

Following the administration of either intracoronary or intravenous streptokinase it became clear that reperfusion could be established in between $55 \%$ and $80 \%$ of cases but the next obvious question to be posed was whether this reperfusion had any impact on patient survival and ventricular function. Unfortunately all of the early studies were too small to answer these questions

(C) The Fellowship of Postgraduate Medicine, 1988 
but a pooled assessment of these studies by Yusuf ${ }^{16}$ suggested that there was an increase in survival of $10-15 \%$ and a significant improvement in global and regional left ventricular function following reperfusion. The first large study to clearly outline the true benefit of this therapy, however, was the GISSI study. ${ }^{22}$ In this study 31,826 patients were screened for entry and 11,806 patients randomized to receive either placebo or one and a half million units of streptokinase infused intravenously over one hour. Short term (3 weeks) mortality was $13 \%$ in placebo group and $10.7 \%$ in treated group $(P<0.02)$, a total reduction in mortality of $17 \%$. Subgroup analysis revealed more interesting findings in that the greatest improvement in survival occurred in those patients treated within 3 hours of infarction (mortality $9.2 \%$ vs $12 \%$ ). In the small number of patients treated in the first hour following onset of pain (1000 patients) mortality was $8.2 \%$ in the treated group and $15.4 \%$ in the untreated group, a $46 \%$ improvement in the chances of survival. The late results of the GISSI study have now been published ${ }^{23}$ and this improvement in early mortality persists to one year.

The importance of early treatment was echoed by the results of another study reported by the Netherlands Interuniversity Group, ${ }^{24,25}$ who demonstrated a reduction in infarct size of $51 \%$ in patients treated within one hour of onset of symptoms, $31 \%$ in those treated within 1-2 hours and $13 \%$ in those treated between $2-4$ hours. In this study, improvement in global left ventricular function was also documented in all groups but this was greatest in those patients treated early.

Both the GISSI study and the Netherlands Interuniversity study looked also at the relative benefits for thrombolytic therapy for anterior and inferior infarctions. The clear message to emerge was that although inferior infarcts may obtain some benefit, particularly if treated in the first 2 hours after onset of symptoms, it is the patients with anterior infarction who benefit most in terms of both improvement in left ventricular ejection fraction and improvement in survival.

In the last few weeks, results of the Oxford based ISIS 2 study have been published.* In this study, as in the GISSI study and the Netherlands Interuniversity study, intravenous streptokinase produced a significant reduction in early mortality after myocardial infarction; this reduction could be enhanced by the simultaneous administration of oral aspirin.

*ISIS 2 (Second International Study of Infarct Survival) collaborative group. Randomized trial of intravenous streptokinase, oral aspirin, both or neither among 17,187 cases of suspected acute myocardial infarction: ISIS 2. Lancet 1988, ii: 349-360.
The last few years have seen the development of two new agents with theoretical advantages over streptokinase, namely tissue plasminogen activator (tPA $)^{26-28}$ and acylated plasminogen streptokinase complex (APSAC). ${ }^{29,30}$ Tissue plasminogen activator (tPA) is a naturally occurring activator of thrombolysis which is now available in therapeutic quantities as a result of gene cloning. It is given by intravenous infusion and its great advantage is its clot selectivity due to the fact that it binds most effectively to plasminogen in the presence of fresh fibrin; this - in theory at least - gives minimal disturbance to the haemostatic system in the rest of the body. In large trials ${ }^{26-28}$ tPA has been compared with both intravenous streptokinase and placebo and shown to be at least as effective in achieving patency, if not more so, than intravenous streptokinase. One problem that has been noted however is a tendency to early vessel reocclusion perhaps due to the agent's short plasma half life; more complex infusion regimes are therefore currently being evaluated. As to clot specificity, all the large tPA trials have shown less generalized haemostatic upset with tPA than with streptokinase as assessed by measurements of plasma fibrinogen or fibrinogen degradation products, but interestingly the instance of major bleeding complications is similar in the two agent groups.

APSAC is also theoretically more specific than streptokinase for fibrin bound in clot and has the advantage over other agents that it can be given as a single intravenous injection over 5 minutes. An interim analysis of 1004 patients entered into a control trial of this agent ${ }^{30}$ has recently been published showing a significant reduction in mortality over 30 days $(32 / 502$ patient deaths given APSAC; $61 / 502$ patient deaths given placebo); the preliminary data suggests continuation of benefit to one year.

At present, however, we are not in a position to say which agent - streptokinase, tPA or APSAC is best, as theoretical benefits have not been borne out in clinical practice. It seems unlikely until large cooperative studies have been carried out that a consensus on a single ideal agent will emerge.

\section{Management after thrombolysis}

Re-thrombosis of the atherosclerotic coronary artery might be expected to occur after thrombolysis unless this procedure was followed by either the administration of anticoagulants or antiplatelet drugs or by the performance of a technique such as coronary angioplasty, since about $70 \%$ of reperfused vessels are left with significant coronary artery stenosis at the site of initial occlusion. ${ }^{31,32}$ 
Trials are currently underway to assess the role of formal anticoagulation or antiplatelet agents in this situation but the place of these additional measures at the present time is not yet established.

The question of angioplasty has however already been addressed. It has been known since early studies $^{31,32}$ that $60-80 \%$ of reperfused vessels are left with a significant degree of residual stenosis at the site of initial occlusion after successful thrombolysis. It also appears that the rate of early reocclusion may be related to the severity of stenosis. ${ }^{33}$ It therefore seems logical that following the administration of a thrombolytic agent patients should be submitted to cardiac catheterization with a view to angioplasty of the stenotic lesion. The only major trial to look at this so far is the TAMI $^{34}$ trial in which, after thrombolysis, patients were randomized to either acute or elective PTCA (7 days following thrombolysis). The results show that not only did acute PTCA have no immediate advantages, but it also carried with it a higher rate of requirement for emergency coronary artery surgery. Clearly therefore there is no urgency about referral for angioplasty. Indirect evidence on this point also comes from the GISSI trial in which no further intervention was carried out after initial

\section{References}

1. Silver, M.D., Baroldi, G. \& Mariani, F. The relationship between acute occlusive thrombi and myocardial infarction studied in 100 consecutive patients. Circulation 1980, 61: 219-227.

2. Fulton, W.F.M. The morphology of the coronary thrombotic occlusions relevant to thrombolytic intervention. In: Kaltenbach, M., Gruntzig, A., Rentrop, K \& Bussman, W.D. (eds) Transluminal Coronary Angioplasty and Coronary Thrombolysis. Springer Verlag, Berlin, Heidelberg, New York, 1982, pp 244-252.

3. Davies, M.J. \& Thomas, A.C. Plaque fissuring - the cause of acute myocardial infarction, sudden ischaemic death and crescendo angina. Br Heart $J$ 1985, 53: 363-373.

4. Rentrop, P., de Vivie, E.R., Karsh, K.R. \& Kreuzer, H. Acute myocardial infarction: intracoronary application of nitroglycerin and streptokinase in combination with transluminal recanalisation. Clin Cardiol 1979, 5: 354-356.

5. Schroder, R., Biamino, G., von Leitner, E.R. et al. Intravenous short term infusion of streptokinase in acute myocardial infarction. Circulation 1983, 67: 536-547.

6. Rentrop, K.P. Thrombolytic therapy in patients with acute myocardial infarction. Circulation 1985, 71: $627-631$.

7. Jennings, R.B., Kaltenbach, J.P. \& Smetters, G.W. Enzymatic changes in acute myocardial ischaemic injury. Arch Pathol 1957, 64: 10-16. administration of thrombolytic therapy and in which early benefit persists up to the end of the one year follow-up period. Most likely in the future, patients will undergo exercise testing following administration of a lytic agent and those with a strongly positive exercise test or the early development of symptoms will be those referred on for further evaluation. These points however remain to be established in prospective trials.

\section{Conclusions}

What conclusions then can we draw from analysis of all the above studies? It now seems clear that patients presenting early with definite electrocardiographic evidence of myocardial infarction (especially anterior), other than those with a specific contraindication, should receive a thrombolytic agent. Treatment should be given as soon as possible and certainly within 6 hours of the onset of symptoms. Streptokinase at the present time remains the most widely used agent and although other agents have theoretical advantages these have not as yet been interpreted into definite clinical advantages.

8. Jennings, R.B. \& Wartman, W.B. Reactions of the myocardium to obstruction of the coronary arteries. Med Clin North Am 1957, 41: 3-9.

9. Jennings, R.B., Sommers, H., Smyth, G.A., Flack, H.A. \& Linn, H. Myocardial necrosis induced by temporary occlusion of a coronary artery in the dog. Arch Pathol 1960, 70: 68-78.

10. Kaltenbach, J.P. \& Jennings, R.B. Metabolism of ischaemic cardiac muscle. Circ Res 1960, 8: 207-213.

11. Jennings, R.B., Kaltenbach, J.P., Sommers, H.M., Bahr, G.F. \& Wartman, W.B. Studies of the dying myocardial cell. In: James, T.N. \& Keyes, J.W. (eds) The Aetiology of Myocardial Infarction. Little Brown, Boston, 1963, pp 189-205.

12. Reimer, K.A., Lowe, J.E. \& Jennings, R.B. The wavefront phenomenon of ischaemic cell death, In: Hjalmarson, A. \& Wilhelmson, L. (eds) Management of Myocardial Ischaemia. Molndal, Sweden, 1978, pp 83-95.

13. Lowe, J.E., Reimer, K.A. \& Jennings, R.B. Experimental infarct size as a function of the amount of myocardium at risk. Am J Pathol 1978, 90: 363-376.

14. Reimer, K.A. \& Jennings, R.B. The "wavefront phenomenon" of myocardial ischaemic cell death. $L a b$ Invest 1979 , 40: 633-644.

15. Ward-Kennedy, J. Ritchie, J.L., Davies, K.B. et al. The Western Washington randomised trial of intracoronary streptokinase in acute myocardial infarction. N Engl J Med 1985, 312: 1073-1077. 
16. Yusuf, S., Collins, R., Peto, R. et al. Intravenous and intracoronary fibrinolytic therapy in acute myocardial infarction: overview of results on mortality, reinfarction and side effects from 33 randomised trials. Eur Heart J 1985, 6: 556-585.

17. De Wood, M.A., Spores, J., Notske, R. et al. Prevalence of total coronary occlusion during the early hours of transmural myocardial infarction. $N$ Engl $J$ Med 1980, 303: 897-902.

18. Rentrop, P., Feit, F., Blanke, H. et al. Effects of intracoronary streptokinase and intracoronary nitroglycerin infusion on coronary angiographic patterns and mortality in patients with acute myocardial infarction. $N$ Engl J Med 1984 311: 1464-1468.

19. May, G.S., Furberg, C.D., Eberlain, K.A. \& Geraci, B.J. Secondary prevention after myocardial infarction - a review of short term acute-phase trials. Prog Cardiovasc Dis 1983, 25: 335-359.

20. Intravenous streptokinase in acute myocardial infarction (ISAM) Study Group. $N$ Engl J Med 1986, 314: 1465-1471.

21. Breddin, K., Ehrly, A.M., Fechler, L. et al. Die Kurtzeit Fibrinolyse beim akuten Myokardinfarkt. Dtsch Med Wochenschr 1973, 98: 861-873.

22. Gruppo Italiano per lo Studio della Streptochinasi nell' Infarcto Miocardico (GISSI). Effectiveness of intravenous thrombolytic treatment in acute myocardial infarction. Lancet 1986, i: 397-401.

23. Gruppo Italiano per lo Studio Streptochinasi nell' Infarcto Miocardico (GISSI). Long term effects of intravenous thrombolysis in acute myocardial infarction. Lancet 1987, ii: 871-874.

24. Simoons, M.L., Serruys, P.W., van den Brand, M. et al. Early thrombosis in acute myocardial: limitation of infarct size and improved survival. $\mathrm{J}$ Am Coll Cardiol 1986, 7: 717-728.

25. Serruys, P.W., Simoons, M.L., Suryapranata, H. et al. Preservation of global and regional left ventricular function after early thrombolysis in acute myocardial infarction. J Am Coll Cardiol 1986, 7: 729-742.
26. Verstraete, M., Bernard, R., Bory, M. et al. Randomized trial of intravenous recombinant tissue type plasminogen activator versus intravenous streptokinase in acute myocardial infarction. Lancet 1985, i: 842-847.

27. The TIMI Group. The thrombolysis in myocardial infarction (TIMI) study. $N$ Engl $J$ Med 1985, 312: 932-936.

28. Verstraete, M., Bleifeld, W., Brower, R.W. et al. Double blind randomized trial of intravenous recombinant type plasminogen activator versus placebo in acute myocardial infarction. Lancet 1985, ii: 965-969.

29. Been, M., de Bono, D.P., Muir, A.L. et al. Clinical effects and kinetic properties of intravenous APSAC anisoylated plasminogen-streptokinase activator complex (BRL 26921) in acute myocardial infarction. Int $J$ Cardiol 1986, 11: 53-61.

30. APSAC Intervention Mortality Study (AIMS) Group. Lancet 1988 , i: $545-549$.

31. Serruys, P.W., Wijns, W., van den Brand, M. et al. Is transluminal coronary angioplasty mandatory after successful thrombolysis? Quantitative coronary angiographic study. Br Heart $J$ 1983, 50: 257-265.

32. Uebis, R., von Essen, R., Schmidt, W.G., Franke, A. \& Effert, S. Reststenose nach erfolgreicher selectiver Lyse kompletter thrombotischer Koronaraterienverschluesse beim akuten Myocardinfarkt. $Z$ Kardiol 1985, 74: 519-524.

33. Harrison, D.G., Ferguson, D.W., Collins, S.M. et al. Rethrombosis after reperfusion with streptokinase importance of geometry of individual lesions. Circula tion 1984, 69: 991-996.

34. Topol, E.J. Califf, R.M., Gerorge, B.S. et al. randomized trial of immediate versus delayed elective angioplasty after intravenous tissue plasminogen activator in acute myocardial infarction. $N$ Engl $J$ Med 1987, 317: 581-588. 